\title{
Saúde nas notícias das eleições de Goiás em 2014: mídia, agente social de saúde
}

\author{
Health in the news of Goiás elections 2014: media, social agent of health
}

\author{
Salud en las noticias de la elección de Goiás en 2014: medios de \\ comunicación, agentes sociales de salud
}

\author{
Simone Antoniaci Tuzzo | simonetuzzo@hotmail.com \\ Universidade Federal de Goiás, Programa de Pós-Graduação em Comunicação, Laboratório de Leitura Crítica da Mídia. \\ Faculdade de Informação e Comunicação. Goiânia, Brasil \\ José Antônio Ferreira Cirino | cirino.jaf@gmail.com \\ Universidade Federal de Goiás, Programa de Pós-Graduação em Comunicação, Laboratório de Leitura Crítica da Mídia. \\ Faculdade de Informação e Comunicação. Goiânia, Brasil
}

\section{Resumo}

Este artigo nasce da tensão entre a comunicação e a saúde no discurso midiático, buscando desvelar o significado da saúde apresentado nas notícias que compõem a editoria de Política \& Justiça do Jornal Diário da Manhã, periódico diário goiano. A partir de uma leitura crítica e uma análise das 102 notícias que constituem esse corpus, verificou-se que a saúde é mencionada para fins eleitoreiros, com pouca participação da população como voz direta ou indireta, tratada na maioria das vezes com assuntos de investimentos e serviços públicos (unidades de atendimento em saúde), deixando em segundo plano as orientações e informações sobre saúde pública e preventiva e todas as outras questões inerentes ao complexo sistema de saúde.

Palavras-chave: comunicação; saúde; política; discurso; eleições; mídia; direito social.

\begin{abstract}
This article is born of the tension between the communication and health in the discourse of the media seeking to reveal the meaning of health presented in the news that compose the editorship of policy \& justice of the Diário da Manhã, periodic daily of Goiânia, capital of the state of Goiás. From a critical reading and analysis of 102 news that constitute this corpus, it was found that health is mentioned for policy purposes, with little participation by the population, such as direct or indirect voice, treated in the majority of cases along with matters of investments and public services (health care units), leaving on backstage the guidelines and information on public and preventive health and all other issues inherent to the complex system of health.
\end{abstract}

Keywords: communication; health policy; discourse; elections; media; social right. 


\section{Resumen}

Este artículo nace de la tensión entre la comunicación y la salud en el discurso de los medios de comunicación buscando revelar el significado de la salud presentados en las noticias que componen la editoria de la política \& justicia del Diário da Manhã, periódico diario de Goiânia, capital de Goiás. A partir de una lectura crítica y del análisis de 102 noticias que constituyen este corpus, se constató que la salud es mencionada para fines de política, con poca participación de la población, como voz directa o indirecta, y tratada en la mayoría de los casos con las cuestiones de las inversiones y los servicios públicos (unidades de salud), dejando en segundo plano las directrices e informaciones sobre salud pública y medidas preventivas y todas las demás cuestiones inherentes al complejo sistema de salud.

Palabras clave: comunicación; salud; política; discurso; elecciones; medios de comunicación; derecho social.

Declaração de conflito de interesses: Sem conflito de interesses.

Fontes de financiamento: Pesquisa desenvolvida dentro do Projeto de Pesquisa Rupturas Metodológicas para uma leitura crítica da Mídia entre os Programas de Pós-Graduação da UFG e UFRJ, que integrou a ação transversal no 06/2011 - Casadinho/Procad. O segundo autor também era bolsista CAPES na época da concepção inicial do projeto.

Agradecimento/Contribuições adicionais: Avanço dos artigos apresentados no XXXVIII Congresso Brasileiro de Ciências da Comunicação - Rio de Janeiro e no XVII Congresso de Ciências da Comunicação na Região Centro-Oeste - Campo Grande - MS.

Histórico do artigo: Submetido: 17.jun.2016 | Aceito: 08.out.2016 | Publicado: 23.dez.2016

Licença CC BY-NC atribuição não comercial. Com essa licença é permitido acessar, baixar (download), copiar, imprimir, compartilhar, reutilizar e distribuir os artigos, desde que para uso não comercial e com a citação da fonte, conferindo os devidos créditos de autoria e menção à Reciis. Nesses casos, nenhuma permissão é necessária por parte dos autores ou dos editores. 


\section{Introdução}

Saúde, assim como a comunicação, apesar da profundidade do tema, também é comumente reduzida a opiniões e senso comum para categorizá-la e defini-la através dos olhares de muitos críticos, geralmente sem local privilegiado de fala ou especialização suficiente para tratar do assunto. Almeida Filho ${ }^{1}$ contribui com uma visão multidimensional da saúde, que permeia campos distintos. Da mesma forma, a comunicação parece estar na sociedade como algo de domínio público, em que poucas vezes é compreendida como ciência; e a mídia é posta como plataformas de uso da massa. Conceitos ordinários de comunicação, mídia e saúde colocam este tripé em condição vulgar. Mas, para além disso, a própria mídia, ao ressignificar os conceitos de comunicação e saúde também reorganiza o pensamento coletivo sobre o tema e sobre seus impactos na sociedade. Neste artigo a proposta é de se trabalhar as palavras, os significados, e a relação entre a mídia, a saúde e a comunicação.

Muitas vezes as ideias apresentadas pela mídia constituem-se como verdades pelo fato de estarem midiatizadas e muitas pessoas balizarem suas ações a partir de seus discursos. A predileção por se trabalhar nessa pesquisa com jornal impresso é justificada pelo papel que ele desempenha numa sociedade tecnológica em que a informação passou a ser algo exacerbado, mas a comunicação cada vez mais escassa. Fala-se sobre tudo, discute-se pouco, conclui-se o óbvio, normalmente só aquilo que é de fácil interpretação.

Paim $^{2}$ faz uma distinção explicando que existe o sistema de saúde e o sistema de serviços de saúde. O primeiro é de responsabilidade de diversos agentes da sociedade, entre eles a própria mídia, as escolas, indústrias, universidades etc., por se tratar de um sistema mais amplo e complexo de funcionamento da saúde. O que sugere que a mídia possui um papel fundamental nessa questão, com vistas a contribuir para o funcionamento do sistema de saúde. Já o sistema de serviços de saúde compreende as tradicionais unidades de saúde, hospitais, postos de saúde etc., e se conhece como a tradução mais direta do Sistema Único de Saúde - SUS.

A Carta de Ottawa ${ }^{3}$, documento apresentado na Primeira Conferência Internacional sobre Promoção da Saúde, em 1986, apresenta um tópico intitulado mediação, com a proposição de que a ação de promover a saúde precisa ser alinhada em um âmbito macro das instituições sociais, sendo a mídia, um dos aparelhos citados, passíveis de engendrar estratégias para cumprir os objetivos no quesito promoção da saúde.

É nessa premissa que este trabalho avança para a elaboração de um conceito da mídia como agente social de saúde, que junto com as universidades, escolas, e outros aparelhos ideológicos formam o complexo sistema de saúde, que vai além das práticas de execução de atendimento e mistura-se com diversas outras áreas, entre elas a comunicação. A pesquisa se justifica com base no entendimento de que a mídia é um agente social de saúde, sendo a indústria da informação um dos agentes da sociedade que podem contribuir para o complexo sistema da saúde ${ }^{2}$.

Nesse espaço de discussões, foi realizado um estudo para compreender o discurso que colabora para a formação da representação sobre saúde através das páginas de Política \& Justiça do Jornal Diário da Manhã no período das eleições de 2014. Essa editoria foi escolhida justamente por não ser um espaço direcionado para o tema da saúde, mas sim para o outro assunto interseccionado - a política - com o intuito de compreender os sentidos elaborados no contexto do período eleitoral, momento com forte potencial para a abordagem de tópicos dos direitos sociais.

A opção pelo jornal impresso justifica-se por ser um dos principais itens constitutivos do complexo midiático e servir de base para a maior parte dos demais veículos como rádio, televisão e internet. Muitas vezes as pessoas não precisam ler jornal impresso para saber o que ele traz como tema relevante, pois essa plataforma é insumo para as principais notícias de rádio e TV todas as manhãs e a capa do jornal impresso é difundida maciçamente para aqueles que não sabem ler ou que não possuem a prática da leitura de jornal. 
Boa parte do jornal impresso é propagado pelos veículos de forte penetração social, mas com um agravante, a presença do locutor de rádio ou do apresentador de televisão que se coloca como um leitor intérprete que poderá modificar o conteúdo do jornal, adjetivando, dando ênfase e fazendo recortes. Assim, sendo a mídia um simulacro de realidade, os conteúdos dos jornais impressos são o simulacro de uma realidade, ressignificados pelos leitores apresentadores que difundirão a notícia.

Dentro da pesquisa há ainda um interesse em se verificar como os discursos midiáticos tratam o cidadão e a relação entre a saúde e a cidadania, partindo-se do pressuposto que a saúde é um dos itens básicos de constituição da cidadania plena, ao lado da segurança, do transporte e da educação. A ressignificação da saúde pela mídia apresenta um cidadão ou um subcidadão em busca de saúde? Também por isso a predileção pela editoria de Política \& Justiça, ou seja, a relação entre a cidadania, a saúde e a política que interfere diretamente na ação de saúde. Assim, em tempos de eleição o cidadão é tratado como indivíduo pleno ou um almejante sempre à espera?

\section{As interfaces}

Para entender melhor a relação entre as duas grandes áreas comunicação e saúde é importante ressaltar que os teóricos e pesquisadores desses campos não se limitam apenas a entender as matérias jornalísticas, mas também as campanhas publicitárias, os atos comunicativos e interpessoais que se realizam no atendimento em saúde, bem como todos os processos que levem à circulação/divulgação de informação sobre saúde para diversos públicos.

Por ser um campo compósito4, o “Comunicação e Saúde” está no limiar de cada uma dessas áreas e ao mesmo tempo se configura como um campo de conhecimento que brota nesse ínterim, resguardando características com a fusão de suas peculiaridades em prol do estabelecimento de novas perspectivas de olhares para esses fenômenos, assim como metodologias para pesquisá-los.

De acordo com Lerner5, "ao se falar em comunicação e saúde estamos nos referindo à articulação entre dois campos sociais que apresentam configurações históricas particulares e que estabelecem entre si relações de naturezas variadas". Este artigo trata especialmente da saúde e de como ela é abordada nos veículos midiáticos justamente pela relação intensa e multifacetada que ambos estabelecem ${ }^{6}$, e é sobre essa temática que o trabalho está focado, no entendimento de comunicação e saúde, uma grande área que merece discussões mais aprofundadas e que não se limita aos estudos da mídia, mas compreende-se que os conteúdos noticiosos são rastros solidificados dessas percepções sociais, facilitando pinçar possíveis elucidações.

No campo complexo da relação da mídia com a saúde pública, identifica-se que

a cobertura de saúde na imprensa leva em consideração os contextos de produção de notícia, a lógica capitalista dos veículos de comunicação e os públicos da empresa jornalística. Dentro dessa cobertura, o assunto saúde ganha destaque, pois atende tanto aos requisitos comerciais da empresa de obter audiência quanto de conquistar público - e consequentemente lucro -, pois saúde é um tema que perpassa em todas as classes sociais e também envolve interesses políticos e econômicos, tendo uma ampla repercussão social e fazendo parte permanentemente da agenda midiática ${ }^{7}$.

Ao tratar da representação midiática ou do discurso sobre saúde é importante ressaltar que se trata de um objeto com imbricações mais profundas e complexas do que as que emergem somente nas linhas do texto. As relações estabelecidas são jogos e estratégias de poder que refletem, mesmo que indiretamente, interesses econômicos, políticos e, também, especificamente eleitorais. 
Vislumbrar a compreensão do discurso midiático em relação à saúde torna-se uma necessidade, tendo em vista as diversas ações estratégicas e jogos de poder inter-relacionados proporcionando a criação de sentidos, imagens e percepções sobre o governo, políticos e instituições através da indústria midiática.

A ideia encontra eco em Araújo $^{8}$, Dalmonte ${ }^{9}$ Charaudeau ${ }^{10}$, que trabalham com a relação de poder das instâncias discursivas, explicando que, além de voz, a mídia também possui um capital econômico, social e cultural, tornando-se assim um campo de luta que lhe garante o direito de formular e emitir discursos. O cidadão é colocado como o dominado, com pouco (ou quase nenhum) poder de voz e menos ainda possibilidade de formulação de discursos, tendo em vista que nessa relação os discursos dependem de outros fatores sociais, como a própria educação formal. Destaca-se que a importância da mídia está em seu alcance, mas muito mais do que isso está no seu poder de discurso, muito antes de sua quantidade de audiência em uma sociedade pouco capaz de discursar.

Um dos arcabouços teóricos convocados para a discussão nesse conflito refere-se ao conceito de subcidadania, apresentado inicialmente por Souza ${ }^{11}$, sentido que pode ser identificado nas representações e nos discursos midiáticos referentes à saúde, pois o que é abordado é sempre algo que falta. O cidadão nunca pleno busca o atendimento, ou a qualidade nesse atendimento, ou até mesmo, que o próprio atendimento aconteça. Encarar a subcidadania é aceitar a condição sub em que a sociedade está mergulhada ${ }^{12}$.

O subcidadão não é um acidadão ou não-cidadão, trata-se de um cidadão em condição inferior ao cidadão pleno, um cidadão que não goza de todos os direitos, apenas tem a obrigação de exercer alguns desses direitos - como a obrigação de exercer seus direitos políticos e civis, mas não assistido pelos direitos que lhe dariam melhores condições de vida. Por isso, ao verificar nesta pesquisa o termo subcidadão, é necessário avaliar que se trata especialmente do cidadão que não tem direitos sociais, em especial a saúde pública (de qualidade).

\section{Aspectos metodológicos}

O intuito deste artigo é compreender quais os discursos sobre saúde nas matérias sobre política do jornal Diário da Manhã durante as eleições de 2014, pois entende-se que o período eleitoral é um importante momento, com espaço para discussões e debates dos diversos temas que afligem a sociedade. Então, que tipo de saúde se encontra nas notícias desse veículo?

O período eleitoral é regido por um calendário próprio, sendo que as movimentações sobre as eleições se iniciam no ano anterior, no caso de 2014 as ações começaram em outubro de 2013 e, de fato, o embate político-ideológico na tentativa de se criar e recriar conceitos e representações sobre políticos e suas ações é constante, não acompanha um calendário ou possui tempos determinados, é um fluxo contínuo, mas tem momentos de maior incidência.

Na estruturação metodológica foram considerados quatro aspectos:

1. a definição do tipo de pesquisa;

2. os instrumentos de coleta adequados;

3. a definição da população-alvo para construção da amostra;

4. os métodos de análise.

A escolha pela análise das notícias de um veículo impresso pauta-se em uma pesquisa sobre os hábitos de consumo de mídia pela população brasileira ${ }^{13} \mathrm{em}$ 2014. De acordo com essa pesquisa, o tempo médio que o brasileiro dedica para um jornal é de 1ho5min e "quando é feito o recorte por unidade da Federação, percebe-se que essa média varia de 45 minutos, para os respondentes do estado do Tocantins, até 2h12, para os leitores de Goiás". Ou seja, os goianos são, da população brasileira, os que mais dedicam tempo à 
leitura do meio impresso. Além disso, a mesma pesquisa ressaltou que as notícias e anúncios publicitários do jornal impresso ainda são os mais confiáveis para a população brasileira.

Já a escolha do jornal Diário da Manhã (DM) se deu a partir do interesse dos pesquisadores-autores em aprofundar os estudos sobre esse veículo dando continuidade a outra pesquisa ${ }^{14}$, em que se verificou uma abordagem diferenciada da tradicional abordagem midiática sobre a saúde pública estadual de Goiás. Por isso, torna-se um objeto de estudo que possibilita a compreensão da provável tentativa de modificar a matriz discursiva em relação à saúde. O DM é um jornal diário com abrangência estadual e, à época da coleta - dezembro de 2014 - disponível na íntegra gratuitamente, no formato online.

Para além disso, considerou-se a relação entre o jornal impresso e os demais veículos de comunicação, que o têm como base para alimentar as notícias de rádio, televisão e internet; ou seja, o jornal impresso é fonte de credibilidade para o complexo midiático e por isso de alcance muito maior do que a sua tiragem ou que o público ao qual foi destinado em sua produção. E como não existe formação da opinião pública sem informação, essa relação se torna absolutamente significativa para o que a sociedade pensa ou é pautada para pensar.

Por isso optou-se por uma delimitação para a coleta com vistas ao caráter qualitativo da pesquisa com o objetivo de aprofundar o estudo do fenômeno para descrevê-lo e compreendê-lo em seus desdobramentos, sem pretender uma diversidade numérica quantitativa ${ }^{15}$. Fairclough ${ }^{16}$ orienta que uma das maneiras de obter a amostra é partir de um ponto crítico. Nesse caso em que a discussão permeia o discurso sobre saúde nas eleições de 2014, o ponto crucial passa a ser a votação em seus $1^{\circ}$ e $2^{\circ}$ turnos. Partindo do suposto que há uma intensificação das matérias jornalísticas e das discussões mais críticas antes e depois do dia da votação, como ilustra a Tabela 1, estabelecemos a coleta de dados em dois intervalos:

1. do dia 28 de setembro até 12 de outubro; e

2. do dia 19 de outubro até o dia 02 de novembro; abarcando sete dias antes e sete dias depois do primeiro e segundo turnos, referentes às votações ocorridas nos dias 05 e 26 de outubro de 2014.

Tabela 1 - Amostra para coleta de dados

\begin{tabular}{|c|c|c|c|c|c|}
\hline \multicolumn{3}{|c|}{$1^{0}$ turno } & \multicolumn{3}{|c|}{$2^{\circ}$ turno } \\
\hline $\begin{array}{l}28 / 09 \\
\text { até } \\
04 / 10\end{array}$ & $\begin{array}{l}\text { Ponto crítico: } \\
05 / 10 \\
\text { Votação }\end{array}$ & $\begin{array}{l}06 / 10 \\
\text { até } \\
12 / 10\end{array}$ & $\begin{array}{l}19 / 10 \\
\text { até } \\
25 / 10\end{array}$ & $\begin{array}{l}\text { Ponto crítico: } \\
26 / 10 \\
\text { Votação }\end{array}$ & $\begin{array}{l}27 / 10 \\
\text { até } \\
02 / 11\end{array}$ \\
\hline 7 dias & 1 dia & 7 dias & 7 dias & 1 dia & 7 dias \\
\hline \multicolumn{3}{|l|}{15 dias } & \multicolumn{3}{|c|}{15 dias } \\
\hline \multicolumn{6}{|c|}{30 dias de amostra total } \\
\hline
\end{tabular}

Fonte: Elaborado pelos autores, 2015.

Mesmo com esse recorte ainda se tratava de uma amostra numerosa, pois o jornal possui uma média de 32 páginas de conteúdo (excluindo Classificados) publicadas diariamente e, portanto, levaria ao estudo de 960 páginas na tentativa de cruzar as duas informações (política e saúde), o que inviabilizaria a pesquisa. Dessa maneira, foi estabelecido mais um filtro/recorte: analisar somente as notícias publicadas na editoria Política \& Justiça, tendo em vista que seriam matérias nitidamente voltadas para um dos temas que se pretendia analisar, ocasionando a busca do segundo tema (saúde) dentro dessas notícias. Nessa definição excluíram-se as outras editorias/cadernos que integram o jornal: Cidades, Esportes, Mundo, Economia, Opinião Pública e DM Revista.

A coleta de dados a partir da amostra estabelecida para essa pesquisa ocorreu diariamente através do site do jornal. Foram identificadas 251 páginas (26,14\% do total de páginas que o jornal possui nesse período da amostra) que compõem a editoria Política \& Justiça, sinalizadas com uma caracterização gráfica no topo de suas páginas com os dizeres ‘Eleições 2014 - Sucessão’, devido ao período de eleições. A segunda etapa da 
coleta de dados foi realizada por meio de uma leitura crítica do material publicado nas páginas de Política \& Justiça com o propósito de identificar as matérias que tratavam de saúde e suas diversas possibilidades de conceitos. Após essa varredura, como ilustra o Gráfico 1, foram encontradas 102 notícias que traziam menções diretas/indiretas à saúde e passaram a constituir a amostra final, conforme representação abaixo:

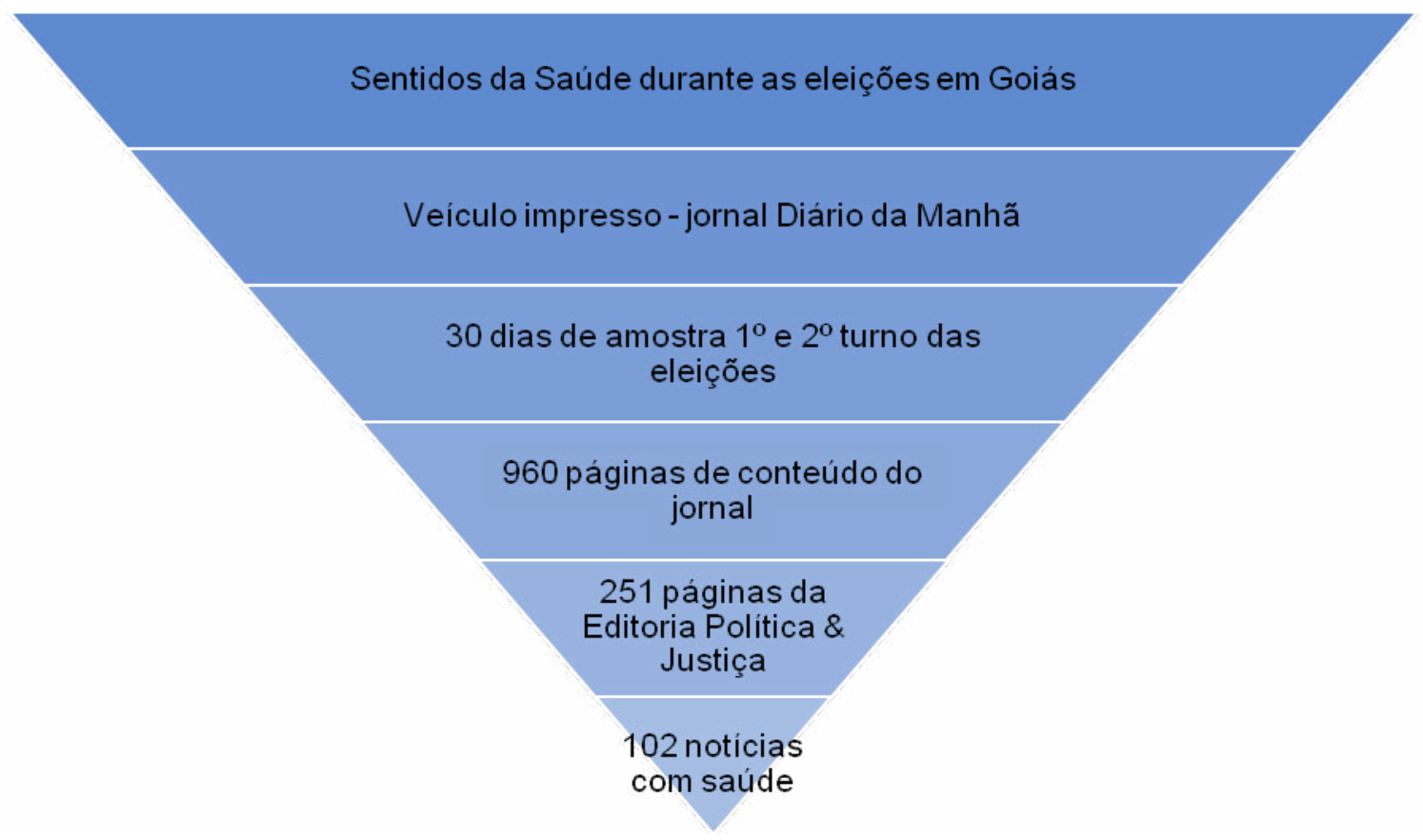

Gráfico1 - Representação gráfica do processo de recorte do corpus Fonte: Elaborado pelos autores, 2015.

Uma planilha para catalogação e estudo dos dados obtidos foi gerada para que, além de uma análise crítica das questões, pudessem ser empreendidos apontamentos sobre algumas características principais. Foram elaborados grupos de análise (Quadro 1) para responder aos seguintes anseios científicos: qual o assunto da notícia em política que aborda saúde? Nessas notícias a abordagem da saúde é direta ou indireta? A quais grupos e subgrupos de saúde se referem essas notícias? Quem tem voz privilegiada nessas notícias, direta e indiretamente, os políticos ou a população? A saúde ali apresentada traz um sentido de cidadania ou subcidadania? ${ }^{13}$

Quadro 1 - Grupos de análise

\begin{tabular}{llllllll}
\hline $\begin{array}{l}\text { Assunto } \\
\text { da notícia }\end{array}$ & $\begin{array}{l}\text { Abordagem } \\
\text { da saúde }\end{array}$ & $\begin{array}{l}\text { Assunto } \\
\text { da saúde }\end{array}$ & $\begin{array}{l}\text { Tema geral } \\
\text { saúde }\end{array}$ & $\begin{array}{l}\text { Subtema } \\
\text { saúde }\end{array}$ & $\begin{array}{l}\text { Vozes } \\
\text { indiretas }\end{array}$ & $\begin{array}{l}\text { Vozes } \\
\text { diretas }\end{array}$ & Cidadania \\
$\begin{array}{l}\text { Grupo das } \\
\text { notícias }\end{array}$ & $\begin{array}{l}\text { Direta ou } \\
\text { indireta }\end{array}$ & $\begin{array}{l}\text { Tema da } \\
\text { discussão } \\
\text { em saúde }\end{array}$ & $\begin{array}{l}\text { Grupo em } \\
\text { saúde }\end{array}$ & $\begin{array}{l}\text { Subgrupo } \\
\text { em saúde }\end{array}$ & $\begin{array}{l}\text { Políticos, } \\
\text { população } \\
\text { ou outros }\end{array}$ & $\begin{array}{l}\text { Políticos, } \\
\text { população outros }\end{array}$ & $\begin{array}{l}\text { Plena, } \\
\text { incompleta, } \\
\text { ambos }\end{array}$ \\
\hline
\end{tabular}

Fonte: Elaborado pelos autores, 2015.

O método escolhido para a análise prevê o olhar dos Estudos Críticos do Discurso ${ }^{17}$ e também da Análise Crítica de Discurso ${ }^{11}$, sem utilizar as ferramentas e categorias da análise tridimensional que estudam a relação do texto, práticas discursivas e práticas sociais em uma abordagem sociolinguística, pois a quantidade da amostra não suportaria uma análise linguística. Tendo em vista que o intuito foi promover uma análise qualitativa com base nas 102 notícias selecionadas, optou-se por realizar uma leitura crítica descritiva das 
menções à saúde e dos discursos sobre ela referentes ao corpus, ou seja, discussões sobre os pontos que despontaram da categorização das matérias e dos resultados obtidos com base na planilha desenvolvida.

Tuzzo $^{18}$ afirma que, quando pensamos em leitura crítica, estamos nos opondo à leitura mecânica, à coleta objetiva de dados, à visão simplória das palavras e seus significados imediatos, à apreensão apática ou meramente da junção de conteúdos. Ao fazermos uma leitura crítica, devemos pensar em uma leitura social firmada em cinco categorias, quais sejam: a compreensão, a interpretação, a reflexão, a crítica e a produção do texto dentro de um contexto social. A leitura crítica não prevê uma pesquisa em si mesma, mas uma interpretação da sociedade. Estudar um produto midiático só faz sentido se aplicado ao contexto em que está inserido.

Outras análises e estudos poderão fluir a partir dessa pesquisa com caráter inicial para a compreensão de como a saúde tem sido abordada na relação com a política nos veículos de comunicação.

\section{A saúde das eleições de 2014 em Goiás}

Verificamos os sentidos propostos pelas notícias de política durante o período das eleições, partindo do pressuposto que o discurso ali expresso tem capacidade de mudanças na realidade social e nas próprias representações do que é saúde ou como a população compreende esse direito social. É importante destacar que, apesar do uso de gráficos e números para a análise, estes só colaboram para verificação de incidência de tais ações, sem o intuito de extrapolá-los a um universo maior, mas sim para entendê-los dentro do fenômeno observado.

Antes dos grupos principais de análise percebemos os sentidos, no gráfico de incidência das menções à saúde na amostra coletada (Gráfico 2). Conforme já dito, foram encontradas 102 notícias mencionando saúde, com uma média de três, quatro notícias/dia, que se dividem de maneira desigual em matéria de quantidade por dia pesquisado. A quantidade total de páginas da editoria também foi desigual durante a coleta da amostra, ou seja, não havia uma uniformidade de páginas, totalizando 251 páginas e uma média de 8,36 páginas/dia.

As menções à saúde no Gráfico 2 não acompanham necessariamente um padrão, devido ao aumento ou diminuição de quantidade de páginas no jornal; porém, evidenciamos dois picos principais de menções à saúde: o primeiro teve seu ápice no dia 03 de outubro, com oito menções, decrescendo até chegar ao ponto de não ter menções no dia 06 de outubro - dia após a votação no primeiro turno, questão compreendida como uma necessidade, por parte do veículo, de reforçar projetos e ações dos candidatos antes da votação, ocasionando o aumento de inserções pré-eleição. Já o segundo pico teve um comportamento diferente: o ápice das menções ocorreu no dia 27 de outubro - dia após a votação do segundo turno - quando houve sete menções à saúde; e após essa data, as menções diminuíram vertiginosamente assim como a quantidade de páginas dedicadas à editoria política. Ao consultar as notícias, percebe-se que a segunda ocorrência do pico refere-se à rememoração dos principais feitos pelo candidato eleito nas diversas áreas, incluindo a da saúde. 


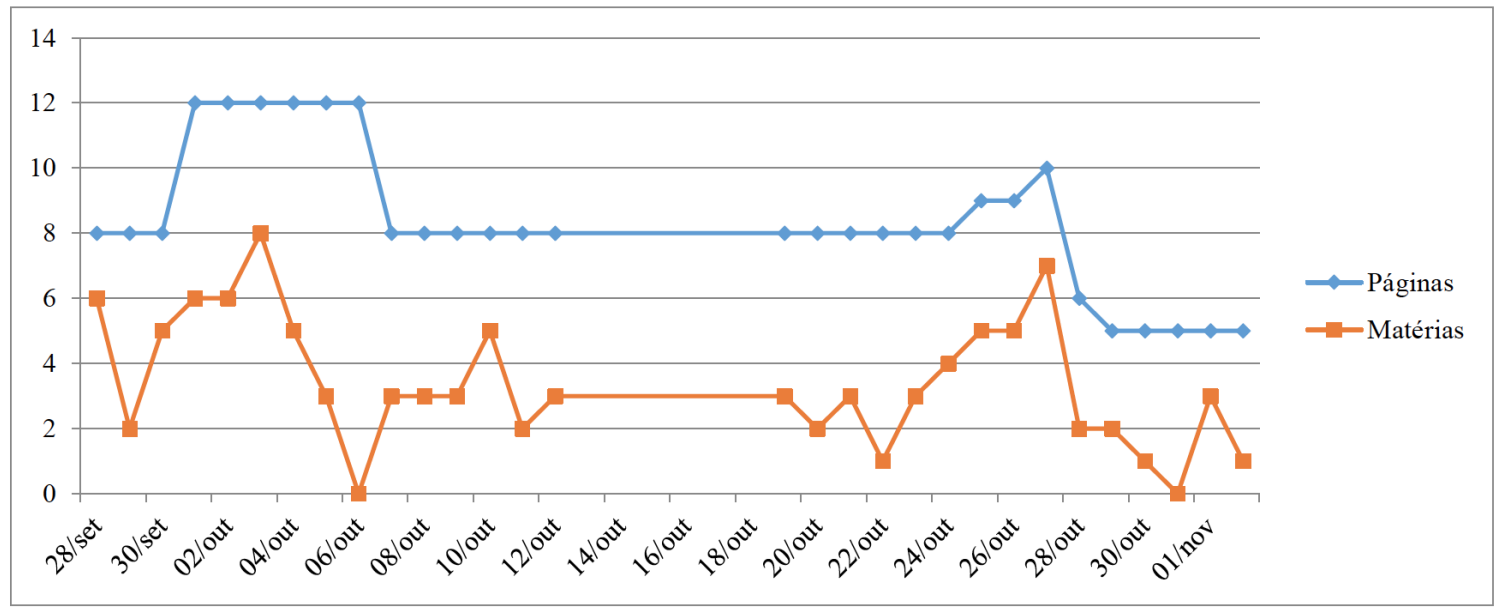

Gráfico 2 - Quantidade de páginas da editoria Política X incidência das menções à saúde Fonte: Elaborado pelos autores, 2015.

A pesquisa também buscou compreender em qual cenário estavam inseridas as notícias sobre saúde ou, em outros termos, em que tipos de notícias políticas havia menção à saúde? As menções à saúde foram concentradas nas notícias:

1. cobertura de campanha (29),

2. entrevistas (11),

3. debates políticos (10),

4. propostas (8),

5. artigos de opinião (6),

6. propaganda eleitoral obrigatória (5),

7. reunião política (5) e

8. ações para a saúde (4), que totalizaram 78 notícias, $76,47 \%$ da amostra.

Os demais grupos de assuntos, apesar de não possuírem maior quantitativo, também foram analisados: três notícias - nomeação de secretários, ressaca eleitoral; duas notícias - corrupção, informações negativas sobre candidato, novos partidos, opinião de político, pesquisa de aprovação; uma notícia - alto custo de vida em Goiânia, apoio político, candidato eleito, falta de investimentos na saúde e na limpeza de Goiânia, implantação de lei, organizações sociais, outubro rosa, problemas no município. 
As notícias foram classificadas em 23 grupos de assuntos, conforme ilustra o Gráfico 3.

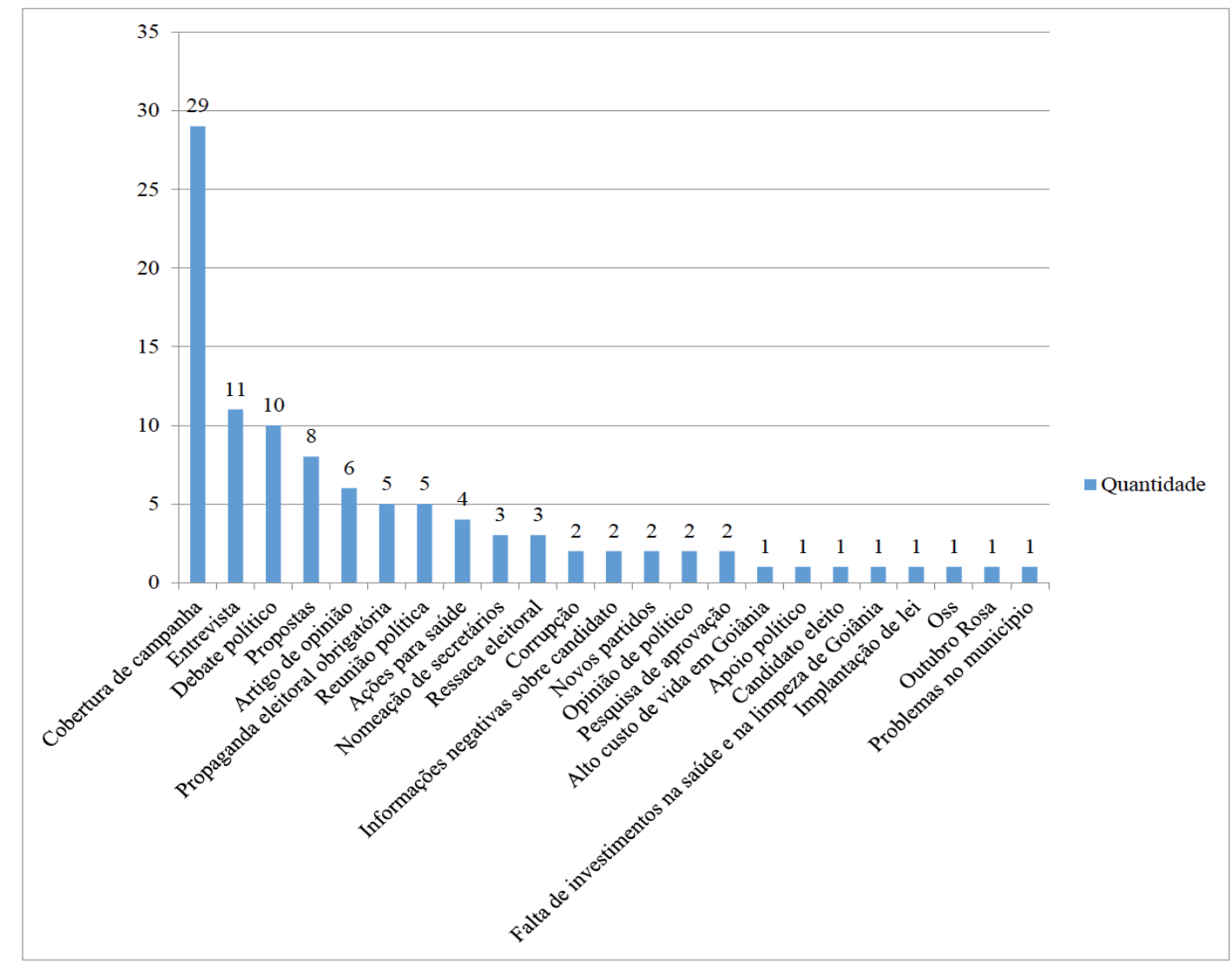

Gráfico 3 - Assuntos das notícias em ordem decrescente de menções Fonte: Elaborado pelos autores, 2015.

As notícias foram catalogadas no sentido de compreender se tratavam o tema de saúde como foco principal ou se a saúde era mencionada de maneira indireta no texto. Nessa busca, encontramos 93 notícias com abordagem indireta e nove com abordagem direta, como ilustra o Gráfico 4.

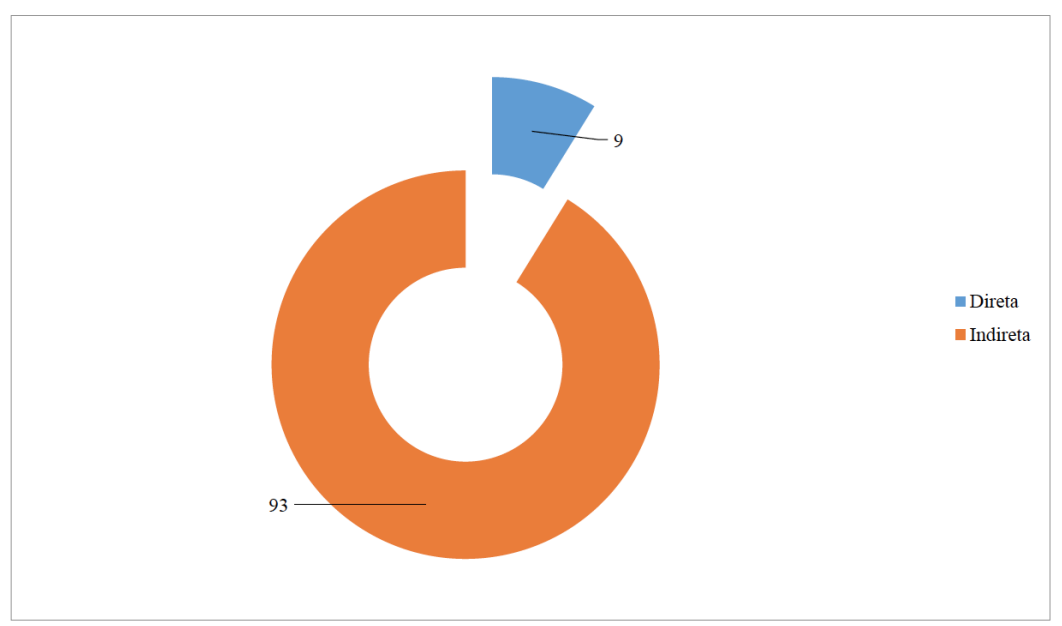

Gráfico 4 - Abordagem da saúde

Fonte: Elaborado pelos autores, 2015.

Esse resultado reflete que, embora a saúde seja um dos principais direitos sociais, foi representada de maneira direta pela notícia apenas em nove de 102 matérias; todas as outras 93 trataram a saúde de maneira indireta, como gancho ou suporte de outros temas. Na relação entre a saúde e a cidadania isso é muito preocupante, pois sabe-se que a saúde pública no Brasil é deficitária e, por isso, necessita de profunda discussão em momentos eleitorais. 
Dos assuntos de saúde abordados nessas notícias, as discussões das notícias que a abordaram diretamente foram: proposta de melhorias para o SUS; população exige nova unidade hospitalar para regiões distantes da capital; obras em andamento em Aparecida de Goiânia; OSs e hospitais públicos em debate na TV assembleia; primeira-dama apoia campanha do Outubro Rosa durante carreatas; repúdio do deputado à limitação de mamografia no SUS para mulheres acima de 50 anos; faltam investimentos na saúde pública municipal em Goiânia; Iris traz possível nomeação de secretário em seu governo e propostas de melhorias e investimentos na área da saúde; críticas ao projeto Mais Médicos.

Já as notícias que trataram a saúde de maneira indireta falaram de diversos assuntos, cada qual com sua temática. Desse modo, para compreender o tema de saúde retratado nas notícias (diretas e indiretas), investigamos quais eram os grupos principais de temas e os possíveis subtemas que estariam englobados nelas. Esses grupos indicam explicitamente a forma como a saúde foi abordada nas notícias, e não exatamente o tema geral da notícia. Não foram analisadas questões referentes ao espaço concedido à saúde nessas menções, mas sim qual o teor dessa saúde ali expressada.

Como grupos principais que emergiram da análise das notícias e a quantidade dessas notícias, listamos:

1. investimentos (42);

2. serviços públicos (38);

3. administração (9);

4. saúde pública (7);

5. saúde mental (3):

6. doença (2);

7. humanização (1)

Cada grupo, em ordem decrescente de incidência, abordava as seguintes discussões:

Investimentos - nesse grupo encontramos uma dualidade, ou uma polaridade, que foi identificada em um contexto geral quanto ao posicionamento desse veículo de comunicação no que se refere à saúde. Por um lado, investimentos em saúde, valorização dos profissionais, obras realizadas na saúde, uma saúde que tem qualidade e é eficiente. Por outro, falta de investimentos em saúde, falta de médicos, profissionais desvalorizados, obras inacabadas ou nunca realizadas na área da saúde, falta de hospitais e insumos, e falta de qualidade no atendimento. Numa análise mais pontual, percebe-se que a saúde que tem investimentos é aquela relatada no discurso político da situação, ou seja, do governo que estava no poder (e que também foi reeleito). Por sua vez, a oposição trabalha constantemente no discurso político sobre caos na saúde pública, como a parte em que faltam investimentos. Como contraposição, a própria situação afirma que a saúde estadual tem investimentos e está funcionando, e que a saúde municipal é a que está sendo criticada pela oposição. Nesse entremeio também existem as notícias que pedem proposições de investimentos na saúde, mas essas têm menor incidência e quase sempre se baseiam em declarações dos próprios políticos. Percebese que, diferentemente do que era habitual no senso comum, em discurso sobre a saúde pública ineficiente versus privada eficiente, há hoje no estado de Goiás a polarização entre a saúde estadual eficiente versus a municipal ineficiente. Apesar da polarização, os sentidos de saúde que aqui se sobressaem - devido à maior incidência - são de uma saúde melhor, com mais investimentos e descentralizada - através das diversas obras por todo o estado.

Serviços públicos - nesse grupo foi possível identificar notícias que tratavam da saúde especificamente como um serviço público e seus diversos aparelhos, num sentido mais mecanicista ou tecnicista da saúde, vislumbrando as questões específicas das estruturas de atendimento. Dentre essas estruturas, duas ganharam destaque e apareceram mais vezes nas notícias enfocando as melhorias que elas trariam para a população: o Hospital de Urgências de Goiânia 2 (Hugo 2) e os Centros de Referência e Dependência Química (Credeqs), o primeiro com abordagem direta de melhoria para a saúde de alta complexidade para o estado de Goiás, 
desafogando os atendimentos no Hugo 1, e o segundo trazendo também a questão da segurança pública, por ser uma unidade que tratará de dependentes químicos, unindo dois temas claramente utilizados nas eleições de 2014 em Goiás e em todo o país. Outras unidades também foram citadas nas notícias, basicamente toda a rede Hugo foi foco de diversas menções. A rede Hugo é uma rede de atendimento composta dos hospitais de urgências da rede estadual que, de acordo com as pesquisas - conforme citado nas notícias, possui mais de 90\% de aprovação de seus usuários. Novamente, as notícias incluídas nesse grupo resgatam questões da polarização da saúde municipal ineficiente e estadual eficiente.

Administração - Dentro do grupo administração foram discutidos temas relacionados às Organizações Sociais (OSs) em saúde, de um lado apoiando e valorizando as ações da dita gestão inteligente do SUS - conforme é divulgado pelo governo -, e do outro, o lado opositor, a necessidade de retirar as OSs da administração das unidades de saúde. As OSs na administração da rede Hugo foram um dos principais temas da campanha do governador reeleito. Nos textos que se referem a essa questão foram sempre ressaltados os bons resultados obtidos com a gestão das OSs, com referência principal à qualidade do atendimento.

Saúde pública - Do ponto de vista de uma mídia cidadã, esse é o grupo que poderia ser o mais encontrado nas notícias, mas que de fato não o foi. As notícias que trouxeram essa temática discutiram poucas questões inerentes ao Sistema Único de Saúde e à saúde preventiva, entre elas: a necessidade de projetos e campanhas de saúde voltadas para a juventude; o programa Mais Médicos do governo federal; a lei dos 60 dias - que trata do período limite para atendimento de pessoas com câncer; outubro rosa e exames de mamografia; e o combate à dengue. Cada um desses temas possui um grau de impacto e importância não considerados pelos critérios de noticiabilidade dentro dos textos do jornal, visto que foram priorizados discussões e jogos políticos, ao invés das reais necessidades da população.

Os outros grupos referem-se à saúde mental, discussão voltada simplesmente para a dita 'ressaca eleitoral' pós-eleições e a possível saúde mental dos políticos após esse processo; doença que trouxe duas referências a políticos com problemas de saúde, mas sem uma discussão aprofundada, apenas como relato; e a questão da humanização, que foi encontrada apenas em uma notícia das 102 de corpus analisado. A bandeira da saúde humanizada foi levantada por um político que citou esse ponto em uma matéria relacionada à cobertura de sua campanha, mas também sem traçar propostas ou formas de se alcançar essa humanização.

Outros fatores analisados são as vozes presentes nessas notícias de política que abordam saúde. Como critério de busca foram estabelecidas três opções de vozes diretas ou indiretas: políticos (qualquer candidato ou eleito), população (qualquer pessoa que representasse a voz da sociedade) e outros (órgãos oficiais, especialistas etc.). Assume-se como voz direta aquela utilizada no texto entre aspas e voz indireta aquela apenas citada como a fala de alguém, não fazendo uso direto das palavras do indivíduo, mas fazendo menção à sua ideia, cabendo ao produtor do conteúdo a expressão e escolha de palavras para essa fala.

Os resultados apresentados no Gráfico 5 demonstram que os políticos (58) foram as principais fontes de vozes diretas utilizadas nas notícias analisadas, seguidos de notícias sem expressões de vozes (23) (N/A - não se aplica), políticos e população (9) dividindo espaço, apenas a população (4), outros (7) e outros e a população (1). Ou seja, os principais falantes dentro dessas notícias são os que detêm o poder, a classe política. Por mais que sejam notícias de uma editoria de política e em períodos eleitorais, em uma visão voltada a diminuir o uso ilegítimo do poder $^{12}$, a população poderia ter mais espaço de expressão, possibilitando maior fala, participação e um equilíbrio de vozes. 


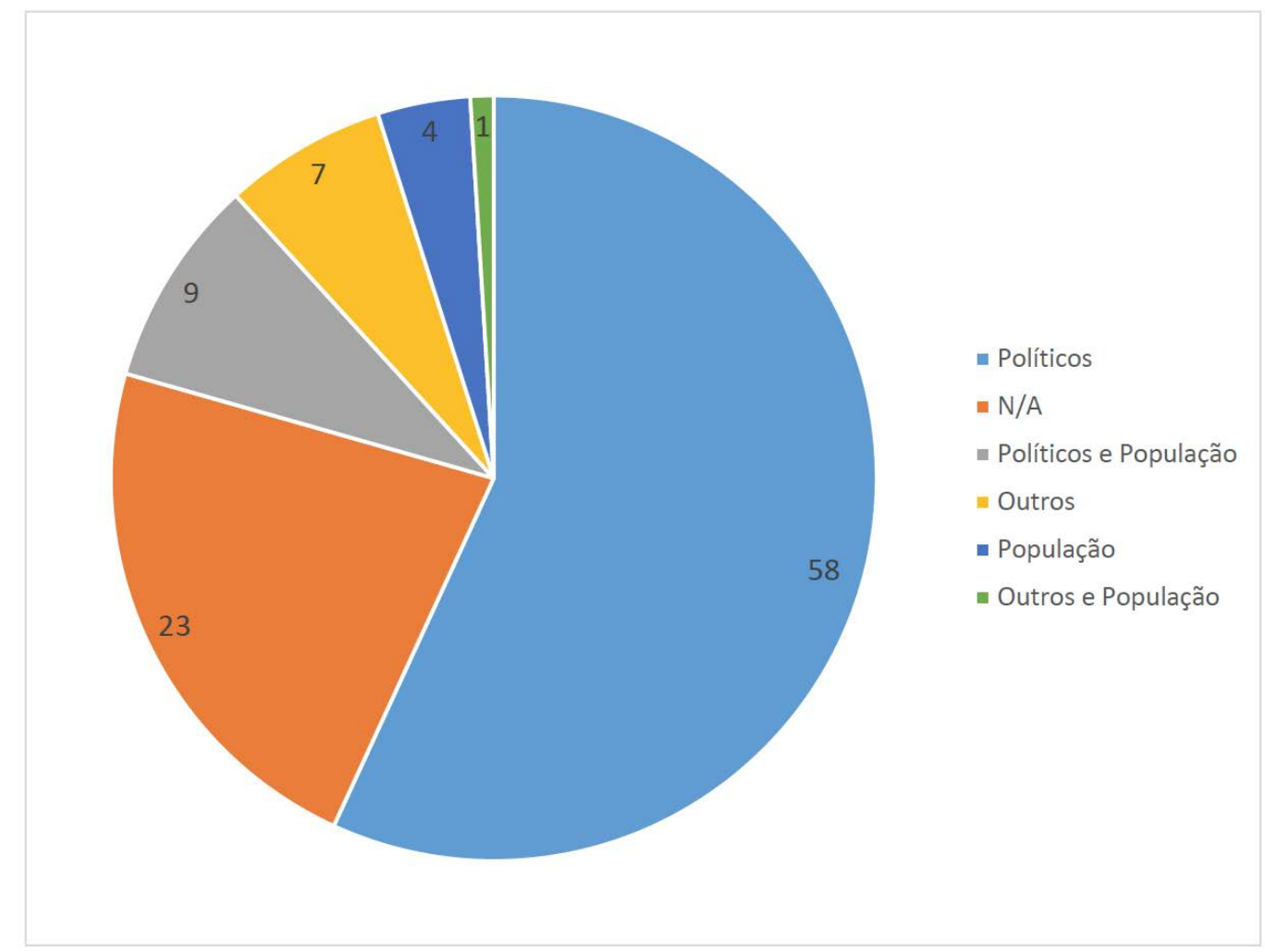

Gráfico 5 - Vozes diretas

Fonte: Elaborado pelos autores da pesquisa, 2015.

Os políticos (48) também foram os principais agentes que se expressaram através da voz indireta nas notícias, seguidos de notícias sem expressões/citações indiretas de fala (41) (N/A - Não se aplica), a população (7) e outros (6). Novamente aqui fica nítido o desequilíbrio de vozes presentes nas matérias sobre saúde ou que citam saúde, como se vê no Gráfico 6.

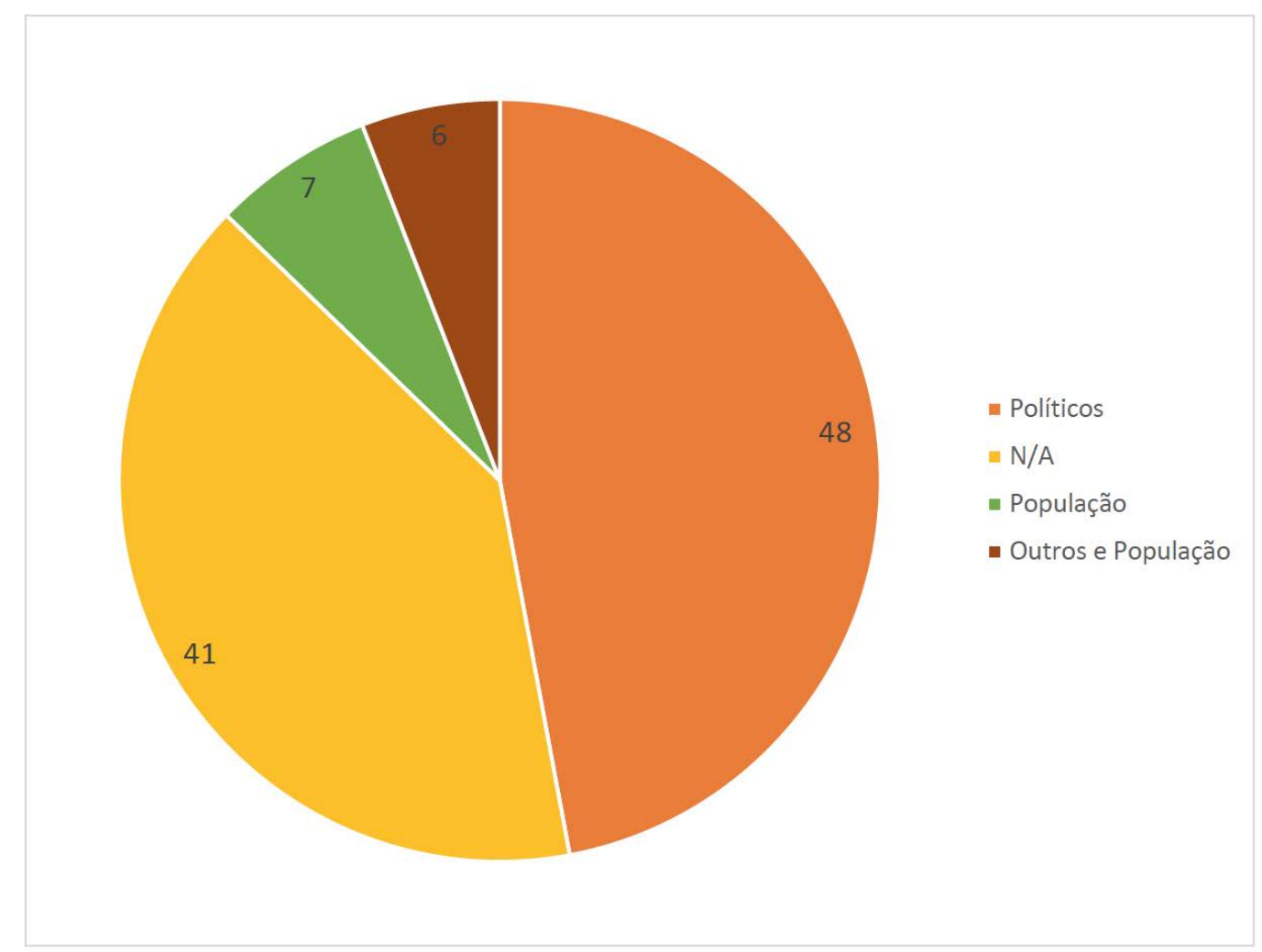

Gráfico 6 - Vozes indiretas

Fonte: Elaborado pelos autores, 2015. 
Na questão relativa à cidadania e na menção à saúde, foi investigado se essas tinham sentido de uma cidadania plena ${ }^{11}$ - na qual as pessoas são cidadãs atendidas em suas questões principais, como a educação, saúde e segurança pública, nesse caso específico sobre a saúde; de cidadania incompleta - se o sistema de saúde é falho e seus direitos não são efetivos; havia também a possibilidade de notícias com ambas as menções ou ausente - sem discussões que pudessem fundamentar essa análise. O resultado é ilustrado no Gráfico 7.

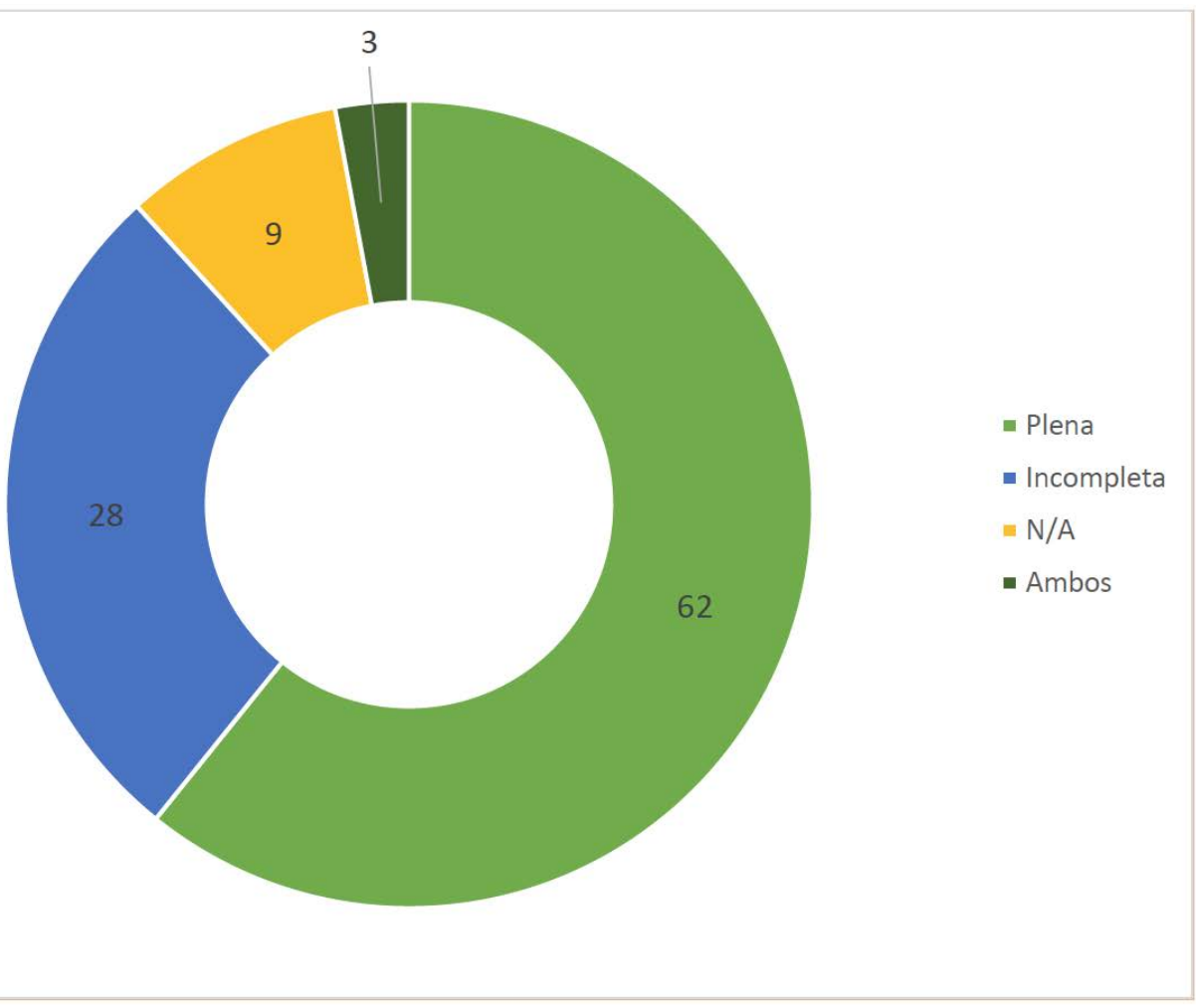

Gráfico 7 - Cidadania X Subcidadania

Fonte: Elaborado pelos autores, 2015.

As notícias tratam prioritariamente de uma saúde ao alcance dos cidadãos e por isso plena (62), mas também existem as que trazem uma abordagem de incompletude (28), em que a saúde não é eficiente, não possui qualidade e precisa de investimentos. Poucas trouxeram a dualidade polarizada da cidadania e subcidadania implícitas em um mesmo texto (3), e em algumas delas não houveram discussões aprofundadas que levariam a um sentido para essa compreensão (9). O mais importante nessa análise da cidadania é entender que a perspectiva de cidadania versus subcidadania proposta pelo olhar midiático advém, nesse caso, de interesses políticos, pois por mais que a área precise de melhorias, para a divulgação em períodos eleitorais ela está em ascendência e sempre melhor. As menções de incompletude ou subcidadania vieram da oposição ao governo ou sobre a saúde municipal de Goiânia, na polarização entre os dois lados do jogo de poder conforme explicitado anteriormente, compondo a impressão de uma saúde boa ou ruim, em termos mais generalistas, a depender de quem escreve sobre ela, de como a enquadram, e em qual esfera (municipal ou estadual).

\section{Considerações finais}

O discurso sobre saúde impresso nas páginas de Política \& Justiça do Jornal Diário da Manhã no período das eleições revela uma dualidade tradicional ao se representar a saúde através da cobertura jornalística: eficiência versus ineficiência. Nessa balança o que diferencia se irá pender para um lado ou para outro são os pesos colocados juntos em cada um desses lados. Para esse objeto de estudo, percebe-se que houve 
uma força maior exercida do lado da saúde eficiente, em que as percepções levam a crer que melhorias e investimentos foram realizados e estão em andamento nessa área..

O tema saúde foi utilizado como apelo de campanha eleitoral e, apesar de ser realmente esse o foco dos políticos durante as eleições, a mídia não tem o papel de só servir de local para publicação dos interesses eleitoreiros, mas sim o de lançar tematizações e agendas que contribuiriam para uma discussão dos direitos sociais na intersecção com a política. Portanto, também é cabível analisar se as notícias coletadas estão atuando com o propósito de narrar fatos e acontecimentos ou com o intuito de divulgar ações políticas, uma publicidade mascarada de jornalismo. O próprio pico de notícias antes da votação do primeiro turno possibilita refletir sobre essa situação.

Outra consideração vem à tona em relação aos principais anseios da população espelhados pelos políticos em seus discursos explicitados através dos textos jornalísticos: a tríade da melhoria - educação, saúde e segurança pública. Educação e segurança pública estiveram na maior parte das menções perto da saúde e ocuparam parte das propostas políticas. Se a saúde faz parte do top três de anseios dos cidadãos e das promessas políticas, as obras e ações nela realizadas acabam sendo motivo de trunfo e uma espécie de troféu. Na maior parte das citações em que foram explicitadas obras, leis e investimentos, todos foram mencionados vangloriando os políticos que os realizaram e não exatamente a obra em si; afinal, tudo o que é realizado pelo governo é da própria população e não o hospital feito pelo governante de um partido ou de outro, da situação ou oposição, como foi abordado.

Saúde é uma área de apelo social, por isso quando recebe apoio e investimentos é foco da cobertura midiática nem sempre com o intuito crítico de analisar a conjuntura, mas de divulgar ações de políticos e não ações políticas. Questões de saúde pública e preventiva apareceram, mas em menor incidência ou profundidade de discussão. Considerando sua essência pública de concessão, o espaço midiático pode ser melhor utilizado para orientar a população sobre o uso do sistema público de saúde, ou sobre campanhas de prevenção. Quanto à população, teve voz em algumas das notícias, mas apenas com elogios e manifestações de agradecimento durante as carreatas dos textos sobre cobertura de campanha.

Em um artigo de opinião do dia primeiro de outubro, que se encontra na amostra estudada, o autor diz que vários políticos estão se elegendo e reelegendo e simplesmente usufruindo dos recursos públicos sem realmente aplicá-los em áreas como a saúde, "matando sonhos e pessoas todos os dias". Exatamente por esse motivo é compreensível esperar mais da mídia, para que esse aparelho ideológico assuma a postura e seu papel de agente social da saúde ao invés de servir apenas como peça nos jogos de poder eleitorais, principalmente em um momento tão crucial para a definição do futuro dos estados e do país como as eleições.

Seja para a divulgação das campanhas nacionais de prevenção de doenças, para a cobertura adequada desses projetos de promoção da saúde, para denúncia ou valorização das ações, discussão dos investimentos propostos se são sub ou superestimados, caso a mídia queira firmar-se como um efetivo agente social de saúde é necessário assumir seu papel frente ao sistema, como um dos aparatos com maior possibilidade de impacto para ambos os lados da força do poder - para a sociedade e para os governantes. Para que possa instruir, informar, educar e orientar sobre os procedimentos e a realidade da situação da saúde no Brasil, ocasionando empoderamento dos indivíduos de modo que, munidos de informações e conscientes dos seus direitos e deveres, possam junto com a mídia exercer poder sobre o governo. E possam mídia e cidadão, juntos, através da divulgação dos acontecimentos e fatos que ocorrem na saúde (de maneira instrutiva sem o habitual preconceito das pautas jornalísticas sobre o tema) pressionar o poder político para que se busquem soluções na área da saúde, mantendo uma relação suficientemente satisfatória. O propósito é gerar uma circularidade de ações positivas, em que se torne possível que o governo atue através da própria mídia como orientador e instrutor, buscando a melhoria almejada do sistema de saúde e da promoção da saúde. 


\section{Referências}

1. Almeida Filho N. O que é saúde [Internet]. Rio de Janeiro: Fiocruz; 2011 [citado 2016 nov. 22]. Disponível em: http://books.scielo.org/id/c4ww5.

2. Paim JS. O que é o SUS [Internet]. Rio de Janeiro: Fiocruz; 2009 [citado 2016 nov. 22]. Disponível em: http://books.scielo.org/id/jmpzg.

3. Carta de Ottawa. Primeira conferência internacional sobre promoção da saúde [Internet]. Ottawa; 1986 [citado 28 set 2016]. Disponível em: http://bvsms.saude.gov.br/bvs/publicacoes /carta ottawa.pdf.

4. Araújo IS. O campo da Comunicação e Saúde: contornos, interfaces e tensões. In: Anais do $36^{\circ}$ Congresso Brasileiro de Ciências da Comunicação; 2013 set 4-7. Manaus; 2013.

5. Lerner K. A pesquisa em Comunicação e Saúde no Brasil: abordagens preliminares. In: Anais do 35 Congresso Brasileiro de Ciências da Comunicação; 2012 set. 3-7. Fortaleza; 2012.

6. Araújo IS, Cardoso JM. Comunicação e Saúde [Internet]. Rio de Janeiro: Fiocruz; 2007 [citado 2016 nov. 22]. Disponível em: http://books.scielo.org/id/kwxbt.

7. Menezes K. Mídia, jornalistas e cidadãos: as representações sociais do SUS[dissertação]. Goiânia: Universidade Federal de Goiás; Faculdade de Informação e Comunicação; 2015.

8. Araújo, IS. Mercado simbólico: interlocução, luta, poder: um modelo de comunicação para políticas públicas [tese]. Rio de Janeiro: Universidade Federal do Rio de Janeiro; Escola de Comunicação; 2002.

9. Dalmonte EF. O jornalismo enquanto formação discursiva: as regularidades enunciativas como estratégia de proposição de verdades. In: Dalmonte, organizador. Teoria e prática da crítica midiática. Salvador: EDUFBA; 2013.

10. Charaudeau P.Discurso das mídias. São Paulo: Contexto; 2013.

11. Souza JA construção social da subcidadania: para uma sociologia política da modernidade periférica. Belo Horizonte: UFMG; Rio de Janeiro: IUPERJ; 2012.

12. Tuzzo SA. O lado sub da cidadania a partir de uma leitura crítica da mídia. In: Paiva RT, Antoniaci S, organizadores. Comunidade, mídia e cidade: possibilidades comunitárias na cidade hoje. Goiânia: FIC/UFG; 2014.

13. Brasil. Presidência da República. Secretaria de Comunicação Social. Pesquisa brasileira de mídia 2014: hábitos de consumo de mídia pela população brasileira. Brasília: Secom; 2014.

14. Cirino JAF,TuzzoSA. Antropomorfização, institucionalização e heroificação: a mudança de enquadramento e abordagem jornalística sobre um hospital estadual de Goiás. In: Cirino JAF, Braga CF, organizadores. Comunicação, cidadania e cultura. Goiânia: PPGCOM/FIC/UFG; 2015.

15. Goldenberg M. A arte de pesquisar: como fazer pesquisa qualitativa em ciências sociais. Rio de Janeiro: Record; 2000.

16. Fairclough N. Discurso e mudança social. Brasília: Editora Universidade de Brasília; 2001.

17. Van Dijk TA. Discurso e poder. 2. ed. São Paulo: Contexto; 2010.

18. Tuzzo, SA. Os sentidos do impresso. Goiânia: UFG/FIC; 2016. 